\title{
Association between insulin-like growth factor- binding protein-3 polymorphism -202 A/C and the risk of prostate cancer: a meta-analysis
}

This article was published in the following Dove Press journal:

OncoTargets and Therapy

6 September 2016

Number of times this article has been viewed

\section{Zhiqiang Qin,,2,* Xiao Li, ',* Jingyuan Tang, ${ }^{2, *}$ Xuping Jiang, ${ }^{2}$ Yajie $Y u,{ }^{2}$ Chengming Wang, ${ }^{2}$ Weizhang $\mathrm{Xu},{ }^{3,4}$ Yibo Hua, ${ }^{2}$ Bin Yu, 'Wei Zhang ${ }^{2}$ \\ 'Department of Urologic Surgery, The Affiliated Cancer Hospital of Jiangsu Province of Nanjing Medical University, ${ }^{2}$ Department of Urology, The First Affiliated Hospital of Nanjing Medical University, ${ }^{3}$ Department of Thoracic Surgery, The Affiliated Cancer Hospital of Jiangsu Province of Nanjing Medical University, ${ }^{4}$ Jiangsu Key Laboratory of Molecular and Translational Cancer Research, Cancer Institute of Jiangsu Province, People's Republic of China \\ *These authors contributed equally to this work}

Background: Some previous studies have investigated the relationship between insulin-like growth factor-binding protein-3 polymorphism and prostate cancer ( $\mathrm{PCa}$ ) susceptibility; however, the findings from those studies remain inconsistent. Hence, the aim of this meta-analysis was to provide a more reliable conclusion about such associations.

Methods: A meta-analysis based on twelve studies was conducted, and 8,341 PCa cases and 7,734 controls were included in this analysis. All relevant studies published till February 1, 2016, were identified by searching the databases such as PubMed, EMBASE, and Web of Science. Data were pooled by odds ratios (ORs) with $95 \%$ confidence intervals (CIs) in order to assess the strength of such associations. Publication bias was evaluated using Begg's funnel plots and Egger's regression test.

Results: Several articles provided data only for particular genotypes; therefore, only dominant model analyses were carried out for all of these studies. Initially, the results from this analysis indicated that $\mathrm{rs} 2854744$ was not associated with PCa susceptibility (OR $=1.12,95 \%$ $\mathrm{CI}=0.996-1.2$ ). However, after excluding one study due to its heterogeneity and publication bias, a significant relationship was detected between rs 2854744 and PCa risk (OR $=1.10,95 \%$ $\mathrm{CI}=1.03-1.17)$. When stratified by genotyping method, significant results were detected only in the Sequenom method group $(\mathrm{OR}=1.13,95 \% \mathrm{CI}=1.04-1.22)$. Moreover, the results from a subgroup analysis that was conducted by using source of controls were significant only in the population-based control group.

Conclusion: This meta-analysis suggested that the insulin-like growth factor-binding protein-3 polymorphism -202 A/C was associated with PCa susceptibility.

Keywords: IGFBP3, gene polymorphism, prostate cancer, meta-analysis

\section{Introduction}

Prostate cancer $(\mathrm{PCa})$ is the most frequent malignancy and the second leading cause of cancer-related deaths among men in industrialized countries. ${ }^{1,2}$ There were an estimated 180,890 new PCa cases and 26,120 mortalities in the United States in 2016. ${ }^{1}$ However, the etiology of PCa is still unclear, and a series of potential risk factors, such as lifestyle, environment, the endocrine system, advancing age, and genetic factors, might have an effect on the risk of $\mathrm{PCa}^{3-7}$ Recently, increasing numbers of studies have found that genetic factors might have an association with the development of PCa, and this result may lead to potential diagnostic and therapeutic methods. ${ }^{8}$ Accordingly, it was revealed that common genetic polymorphisms such as single-nucleotide polymorphic variants might be associated with sporadic cases of $\mathrm{PCa}{ }^{9}$ 
Insulin-like growth factor-binding protein-3 (IGFBP3), an important member of the IGFBP family, has been identified as a putative tumor suppressor with multifunctional roles in the IGF axis. ${ }^{10,11}$ This gene encodes a protein with an IGFBP domain and a thyroglobulin type-I domain, and this is a single-copy gene with five exons located on chromosome $7 \mathrm{p} 13 \mathrm{p} 12 .{ }^{11}$ IGF-I is a mitogen that is associated with cell proliferation, differentiation, and apoptosis. ${ }^{12}$ IGFBP3, a major binding protein of circulating IGF-I with high affinity and specificity, regulates its biological activities and exerts antiproliferative or proapoptotic effects through IGF-dependent and IGF-independent mechanisms in vitro. ${ }^{13,14}$ In previous studies, some researchers discovered a few single-nucleotide polymorphic variants-type polymorphisms in the promoter region of the IGFBP3 gene. Among them, A $>$ C substitution at locus -202 (rs2854744) was the most significant, which was closely correlated with the level of circulating IGFBP $3 .{ }^{15}$ Moreover, a growing number of studies have reported on IGFBP3, and more attention has been paid to its effect on carcinogenesis, because low circulating levels of IGFBP3 have been strongly related to an increased risk of various human cancers, including PCa. ${ }^{16-27}$ Thus, it was hypothesized that rs 2854744 was likely to have an effect on prostate carcinogenesis.

Several studies have been conducted to elucidate the possible association between the IGFBP3 polymorphism and the risk of PCa. However, to date, the results remain inconsistent or even contradictory. Hence, the present metaanalysis based on all accessible case-control studies aimed to critically evaluate the relationship between rs 2854744 and PCa risk.

\section{Materials and methods}

All relevant studies published till February 1, 2016, were identified by searching the databases such as PubMed, EMBASE, and Web of Science. The keywords used for the search included "Insulin-like growth factor-binding protein-3," "IGFBP3 polymorphism," "rs2854744," "-202 A/C," and "prostate cancer." All publications were evaluated to retrieve the most eligible literature. We handsearched the reference lists of reviews or original articles to find additional potential studies to be included in this analysis. Furthermore, only the most recent or complete studies were selected for this meta-analysis, if the studies had partly overlapping content or covered the same subjects.

The following were the inclusion criteria: 1) a casecontrol design, 2) detected relationship between the IGFBP3 polymorphism -202 A/C and PCa susceptibility, and 3) sufficient data for the calculation of an odds ratio (OR) with
95\% confidence interval (CI). In addition, the major exclusion criteria were as follows: 1) non-case-control studies, 2) lack of available and complete data for genotype frequency, and 3) previous duplicated publications.

\section{Data extraction}

Two investigators (Qin and $\mathrm{Li}$ ) independently reviewed each manuscript and extracted useful data to determine whether an individual study met the inclusion criteria. Any disagreement would be explored by discussion until a consensus was reached. The following information was obtained from each study in a standardized form: first author's name, year of publication, ethnicity, source of controls (population-based or hospital-based), genotyping method, sample size of cases and controls, genotype frequency of rs 2854744 in cases and controls, respectively, and the results of the Hardy-Weinberg equilibrium test.

\section{Statistical analysis}

The goodness-of-fit $\chi^{2}$ test was used to test Hardy-Weinberg equilibrium, and $P<0.05$ was regarded as significant disequilibrium. ${ }^{28}$ Pooled ORs with $95 \%$ CIs were used to assess the strength of associations between rs2854744 and PCa susceptibility. The fixed effects model (Mantel-Haenszel method) or the random effects model (DerSimonian-Laird method) was used in the meta-analysis. If heterogeneity was found, the random effects model would be used. Otherwise, the fixed effects model would be used. A few studies provided data only for particular genotypes; ${ }^{18}$ therefore, only the dominant model analyses were carried out for all the included studies. In addition, a subgroup analysis was carried out by using genotyping method and the source of controls. A sensitivity analysis was conducted by finding the stability of results to reflect the influence of the individual data sets on the pooled ORs. The influence of publication bias was checked by Begg's funnel plot and examined further by Egger's linear regression test. $P<0.05$ was considered statistically significant. ${ }^{29}$ All statistical data handling processes were carried out by using Stata software (Version 12.0; StataCorp LP, College Station, TX, USA).

\section{Results}

\section{Characteristics of the studies}

This meta-analysis included 8,341 cases and 7,734 controls from a total of twelve case-control studies on IGFBP3 polymorphism and PCa risk, ${ }^{16-27}$ and Table 1 lists the detailed data from each study. All the included studies, except for one study, suggested that the distribution of genotypes in the controls was consistent by Hardy-Weinberg equilibrium. ${ }^{22}$ 
Table I Characteristics of individual studies included in the meta-analysis

\begin{tabular}{|c|c|c|c|c|c|c|c|c|c|c|c|c|c|c|c|}
\hline \multirow[t]{2}{*}{ Year } & \multirow[t]{2}{*}{ Surname } & \multirow[t]{2}{*}{ Ethnicity } & \multirow[t]{2}{*}{ soc } & \multirow[t]{2}{*}{ Genotyping } & \multirow[t]{2}{*}{ Case } & \multirow[t]{2}{*}{ Control } & \multicolumn{4}{|c|}{ IGFBP3, case (n) } & \multicolumn{4}{|c|}{ rs2854744, control (n) } & \multirow[t]{2}{*}{ HWE } \\
\hline & & & & & & & AA & AC & CC & $\mathbf{A C}+\mathbf{C C}$ & AA & AC & CC & $\mathbf{A C}+\mathbf{C C}$ & \\
\hline 2015 & Zhang et $\mathrm{al}^{16}$ & Asian & PB & Sequenom & 3,132 & 2,489 & 1,926 & 1,059 & 147 & 1,206 & 1,616 & 786 & 87 & 873 & $\mathrm{Y}$ \\
\hline 2014 & Qian et $\mathrm{al}^{17}$ & Asian & $\mathrm{HB}$ & TaqMan & 664 & 702 & 408 & 225 & 31 & 256 & 424 & 246 & 32 & 278 & Y \\
\hline 2011 & Safarinejad et al ${ }^{18}$ & Caucasian & HB & PCR-RFLP & 168 & 336 & 23 & 85 & 60 & 145 & 89 & 163 & 84 & 247 & $\mathbf{Y}$ \\
\hline 2009 & Park et al ${ }^{19}$ & Asian & $\mathrm{HB}$ & PCR-RFLP & 225 & 225 & 128 & 76 & 21 & 97 & 140 & 76 & 9 & 85 & Y \\
\hline 2007 & Hernandez et $\mathrm{a}^{20}$ & African & $\mathrm{HB}$ & PCR-RFLP & 401 & 366 & 112 & 196 & 93 & 289 & 113 & 183 & 70 & 253 & Y \\
\hline 2007 & Hoyo et $\mathrm{a}^{21}$ & Mixed & $\mathrm{HB}$ & PCR-RFLP & 97 & 93 & 17 & - & - & 80 & 23 & - & - & 69 & - \\
\hline 2006 & Cheng et $\mathrm{a}^{22}$ & Mixed & PB & Sequenom & 2,279 & 2,255 & 687 & 1,002 & 590 & I,592 & 720 & 954 & 581 & $\mathrm{I}, 535$ & $\mathrm{~N}$ \\
\hline 2006 & Chen et $\mathrm{a}^{23}$ & Mixed & PB & PCR-RFLP & 213 & 213 & 55 & 91 & 67 & 158 & 47 & 103 & 63 & 166 & Y \\
\hline 2005 & Schildkraut et a ${ }^{24}$ & Mixed & $\mathrm{HB}$ & PCR-RFLP & 100 & 92 & 18 & 55 & 27 & 82 & 23 & 41 & 28 & 69 & Y \\
\hline 2004 & Li et $a^{25}$ & Mixed & $\mathrm{HB}$ & PCR-RFLP & 440 & 479 & 97 & 217 & 126 & 343 & 139 & 225 & 115 & 340 & Y \\
\hline 2003 & Wang et $\mathrm{a}^{26}$ & Asian & $\mathrm{HB}$ & PCR-RFLP & 307 & 272 & 189 & 100 & 18 & 118 & 152 & 105 & 15 & 120 & Y \\
\hline 2003 & Nam et $\mathrm{al}^{27}$ & Mixed & $\mathrm{HB}$ & PCR-RFLP & 483 & 548 & 135 & 233 & 115 & 348 & 145 & 274 & 129 & 403 & $Y$ \\
\hline
\end{tabular}

Notes: The study of Safarinejad et al ${ }^{18}$ (shown in bold) was removed later because of its heterogeneity and publication bias. The dash indicates no data.

Abbreviations: HB, hospital-based controls; HWE, Hardy-Weinberg equilibrium; IGFBP3, insulin-like growth factor-binding protein-3; PB, population-based controls; PCR-RFLP, polymerase chain reaction-restriction fragment length polymorphism; SOC, source of controls.

Figure 1 shows the flowchart of the literature search and selection process. In these studies, three genotyping methods were applied: TaqMan, polymerase chain reaction-restriction fragment length polymorphism, and Sequenom. Furthermore, in order to distinguish between different sources of the control groups, the studies were divided into population-based and hospital-based control groups.

\section{Results of quantitative synthesis}

Overall, initially, the results from this meta-analysis indicated that rs 2854744 was not associated with the risk of $\mathrm{PCa}$ $(\mathrm{OR}=1.12,95 \% \mathrm{CI}=0.996-1.26)$ in a random effects model (Figure 2). Nevertheless, in order to find possible factors that might have affected the results, heterogeneity analysis was performed and publication bias was tested. After excluding

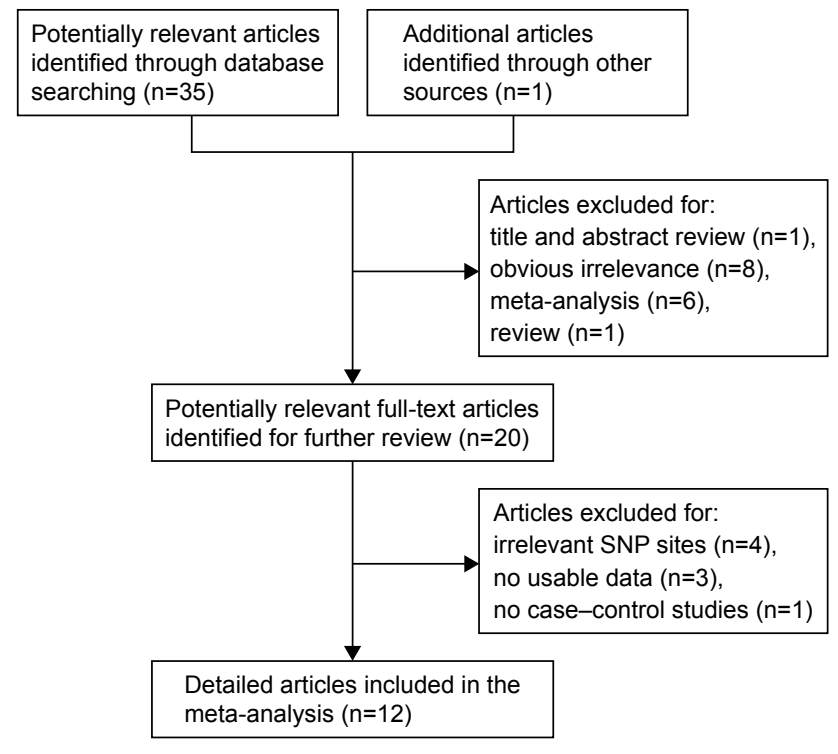

Figure I Flowchart of literature search and selection process. one study because of its heterogeneity and publication bias, the $P$-value was evaluated to be 0.131 , and the fixed effects model was consequently used. Then, the results demonstrated that the rs 2854744 polymorphism was significantly correlated with $\mathrm{PCa}(\mathrm{OR}=1.10,95 \% \mathrm{CI}=1.03-1.17$; Figure 3). Table 2 lists all the relevant results from the present metaanalysis of associations between the rs2854744 polymorphism and PCa risk, after excluding a study by Safarinejad et al. ${ }^{18}$ When stratified by genotyping method, the results were positive only for the Sequenom method (dominant model: $\mathrm{OR}=1.13,95 \% \mathrm{CI}=1.04-1.22$; Figure 4A). In the subgroup analysis that was conducted by using source of controls, the results were significant in the population-based control group (OR $=1.12,95 \% \mathrm{CI}=1.03-1.21$; Figure 4B). Overall, this meta-analysis revealed that rs 2854744 was associated with PCa risk.

\section{Test of heterogeneity}

Before excluding a study by Safarinejad et al, ${ }^{18}$ significant heterogeneity was observed between the included studies $(P<0.001)$. A Galbraith radial plot was used because of the presence of heterogeneity (Figure 5), which indicated that a study by Safarinejad et al ${ }^{18}$ might have generated the observed heterogeneity. After excluding that study from the present analysis, the overall heterogeneity was markedly decreased $(P=0.131)$. Moreover, subgroup analyses were performed to reduce heterogeneity.

\section{Publication bias}

In order to assess the potential publication bias using the data obtained from all the included articles, the Begg's funnel plot and Egger's test were used. Before excluding a study by Safarinejad et al, ${ }^{18}$ the plots were asymmetrically distributed 


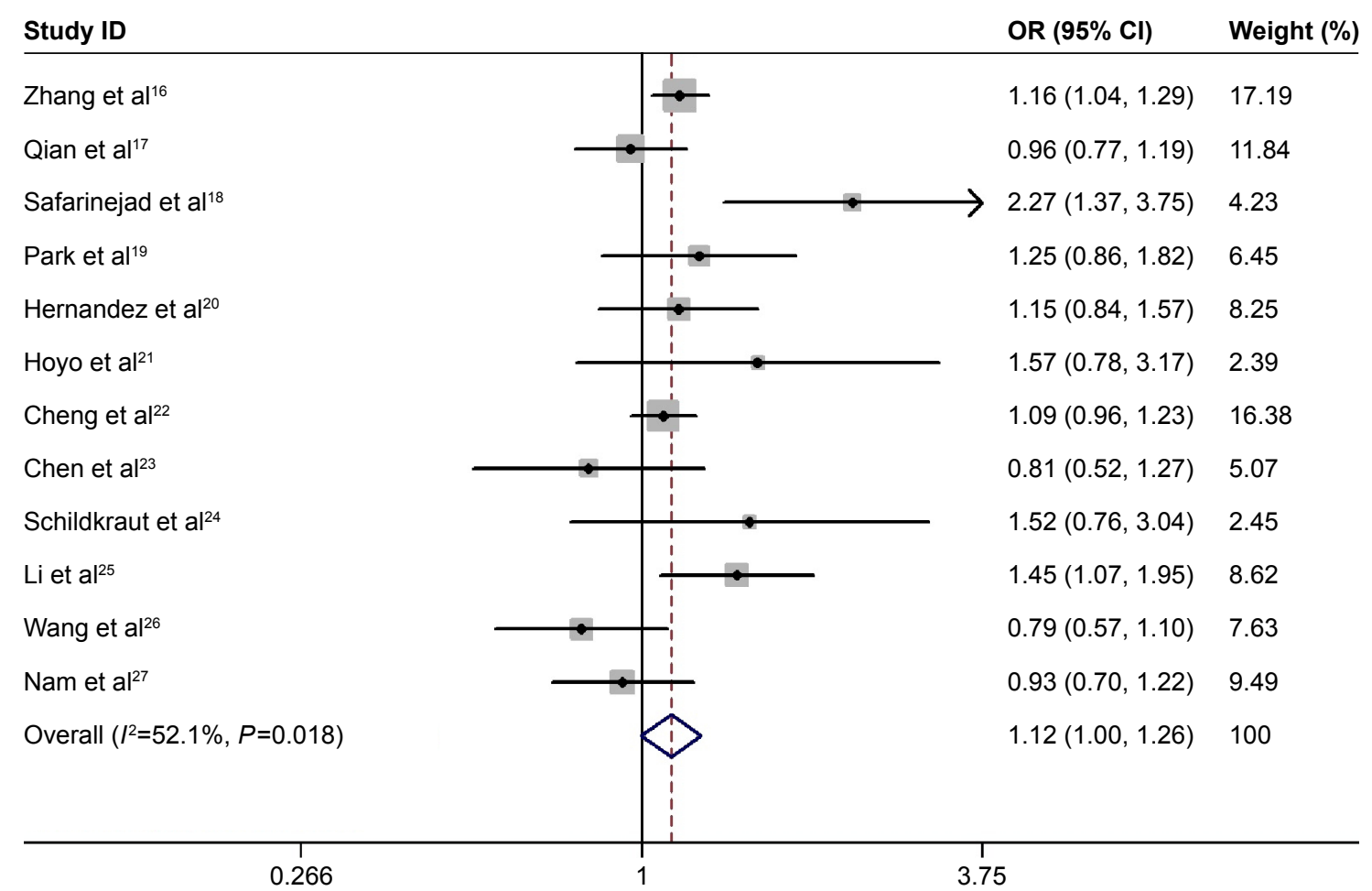

Figure 2 Forest plots of the association between IGFBP3 polymorphism and PCa susceptibility in the dominant model.

Note: Weights are obtained from random-effects model.

Abbreviations: $\mathrm{Cl}$, confidence interval; IGFBP3, insulin-like growth factor-binding protein-3; OR, odds ratio; PCa, prostate cancer.

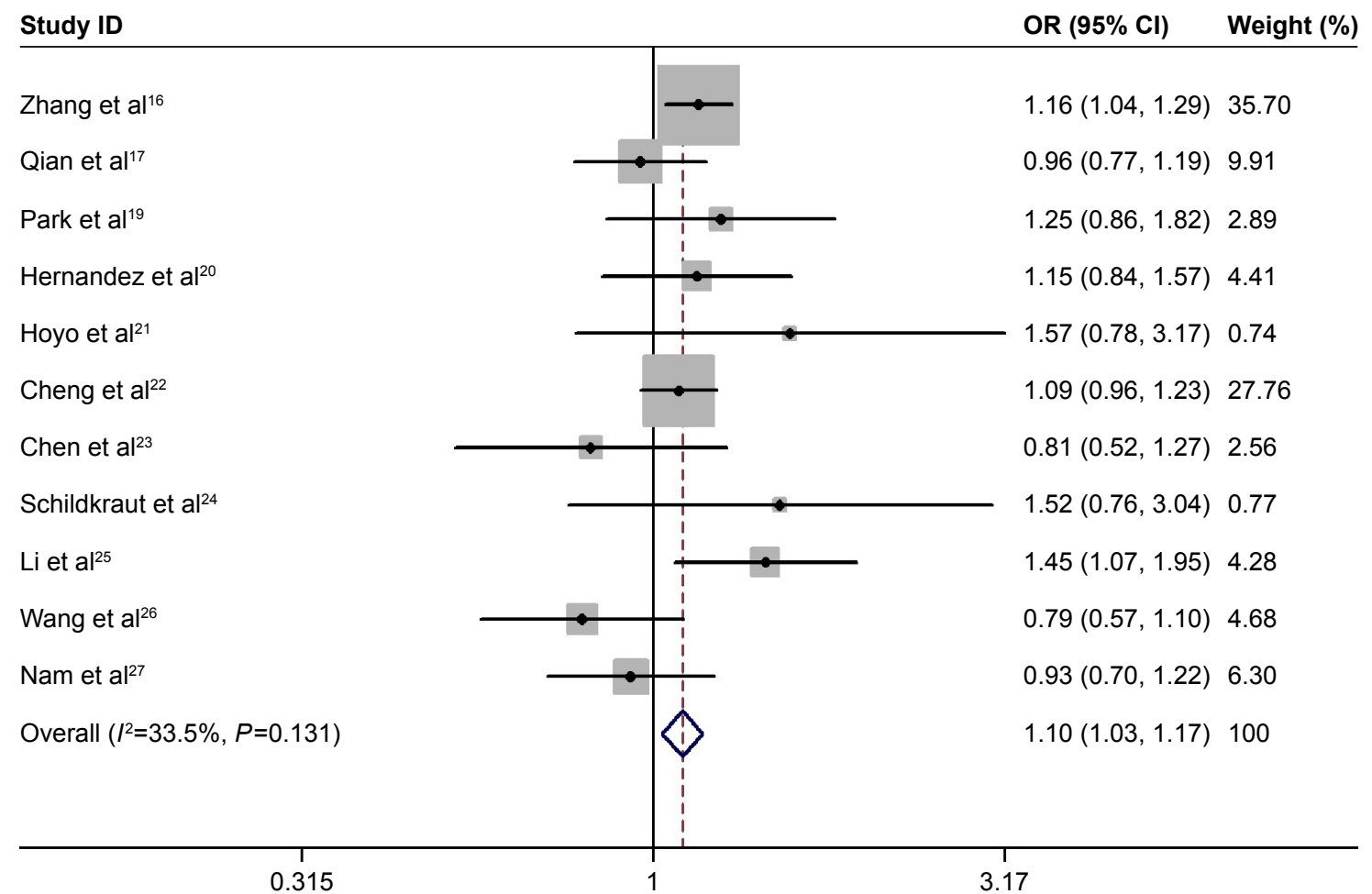

Figure 3 Forest plots of the association between IGFBP3 polymorphism and PCa susceptibility in the dominant model after excluding a study by Safarinejad et al ${ }^{18}$ with heterogeneity and publication bias.

Abbreviations: $\mathrm{Cl}$, confidence interval; IGFBP3, insulin-like growth factor-binding protein-3; OR, odds ratio; PCa, prostate cancer. 
Table 2 Results from the meta-analysis of the association between rs 2854744 polymorphism and prostate cancer risk, after the elimination of a study by Safarinejad et al ${ }^{18}$

\begin{tabular}{|c|c|c|c|c|}
\hline & $n^{a}$ & $\begin{array}{l}\text { Sample } \\
\text { size }\end{array}$ & $\begin{array}{l}\text { VA/AA versus VV; } \\
\text { OR }(95 \% \mathrm{CI}) *\end{array}$ & $P$-value ${ }^{b}$ \\
\hline Total & $\mathrm{II}$ & 16,075 & $1.10(1.03-1.17)$ & 0.131 \\
\hline \multicolumn{5}{|l|}{ Genotyping } \\
\hline TaqMan & I & 1,366 & $0.96(0.77-1.19)$ & - \\
\hline Sequenom & 2 & 10,155 & $1.13(1.04-1.22)$ & 0.45 \\
\hline PCR-RFLP & 8 & 4,554 & $1.10(1.03-1.17)$ & 0.086 \\
\hline \multicolumn{5}{|c|}{ Source of control } \\
\hline PB & 3 & $|0,58|$ & $1.12(1.03-1.21)$ & 0.278 \\
\hline $\mathrm{HB}$ & 8 & 5,494 & $1.07(0.95-1.20)$ & 0.098 \\
\hline
\end{tabular}

Notes: ${ }^{a}$ Number of studies, ${ }^{b} P$-value of $Q$-test for heterogeneity. $*$ Random effects model was used when $P$-value for heterogeneity test $<0.1$; otherwise, fixed effects model was used. The dash indicates no data.

Abbreviations: $\mathrm{Cl}$, confidence interval; $\mathrm{HB}$, hospital-based controls; OR, odds ratio; PB, population-based controls; PCR-RFLP, polymerase chain reactionrestriction fragment length polymorphism.

in the Begg's funnel, exhibiting a potential publication bias (Figure 6A). However, after the elimination of that study, ${ }^{18}$ the shapes of the Funnel plots seemed symmetric and the publication bias was obviously decreased (Figure 6B).

\section{Sensitivity analysis}

Sensitivity analysis was conducted to distinguish the influence of each study on the pooled ORs, by repetition of the meta-analysis with the exclusion of one study at a time. Figure 7 shows the sensitivity analysis of the association, demonstrating that the recalculated OR was not substantially affected using the exclusion method step-by-step. Thus, sensitivity analysis indicated that the results from this present meta-analysis were reliable and robust.

\section{Discussion}

IGFs that correlate the regulation of cell proliferation with apoptosis might influence carcinogenesis. ${ }^{30}$ IGFBP3 is a predominant serum carrier protein for the IGFs and plays an important role in regulating normal and malignant cell growth through the binding of IGF-I, or independently of this mechanism. ${ }^{13,14,31}$ Some previous studies have demonstrated that IGFBP3 reduces cellular proliferation and stimulates apoptosis, mediating the bioavailability of IGF-1 in circulation. ${ }^{13,32}$ The IGFBP3 $-202 \mathrm{~A} / \mathrm{C}$ genetic polymorphism, which is the most common polymorphism, has been

A

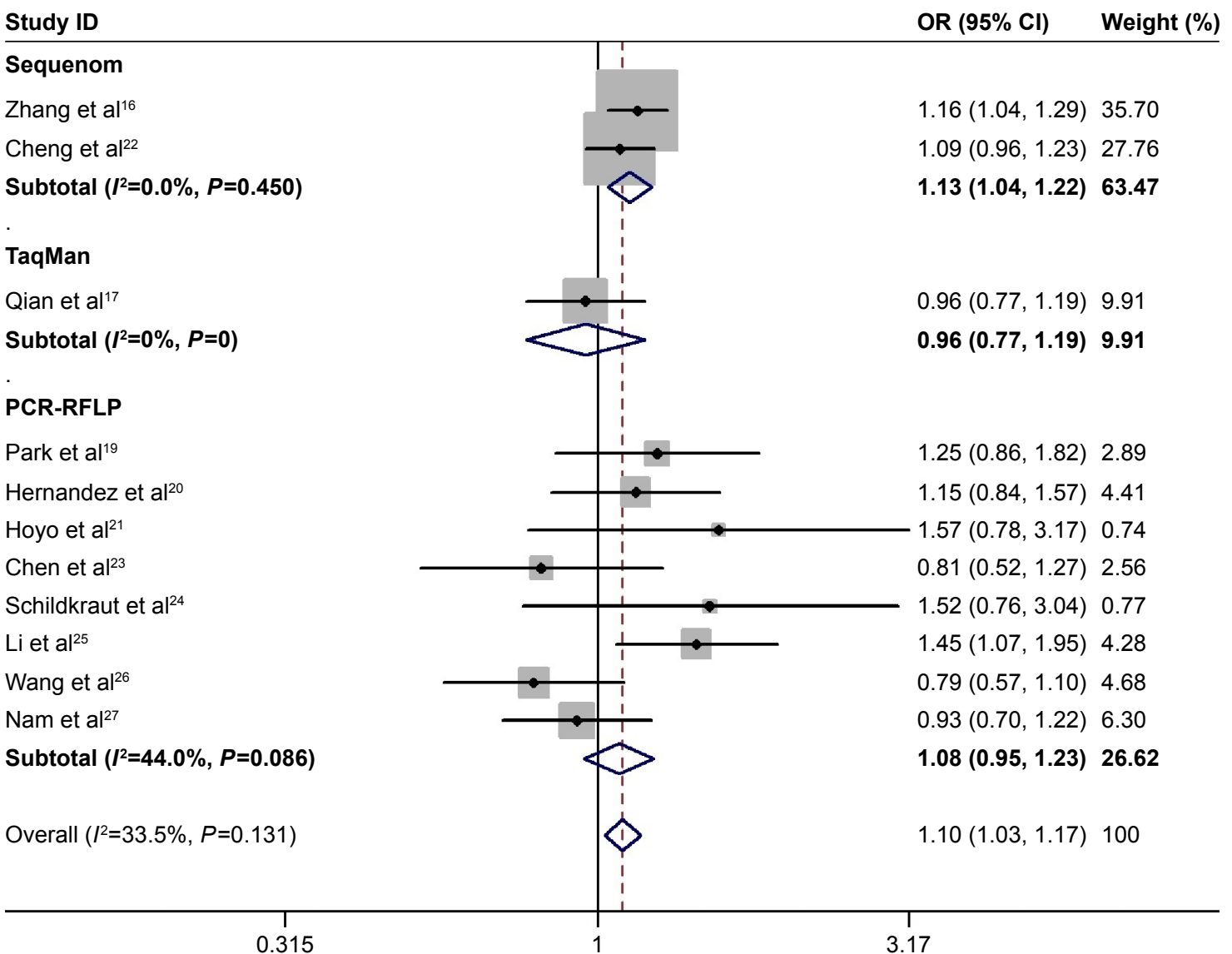

Figure 4 (Continued) 


\section{B}

Study ID

OR $(95 \% \mathrm{Cl})$

Weight (\%)

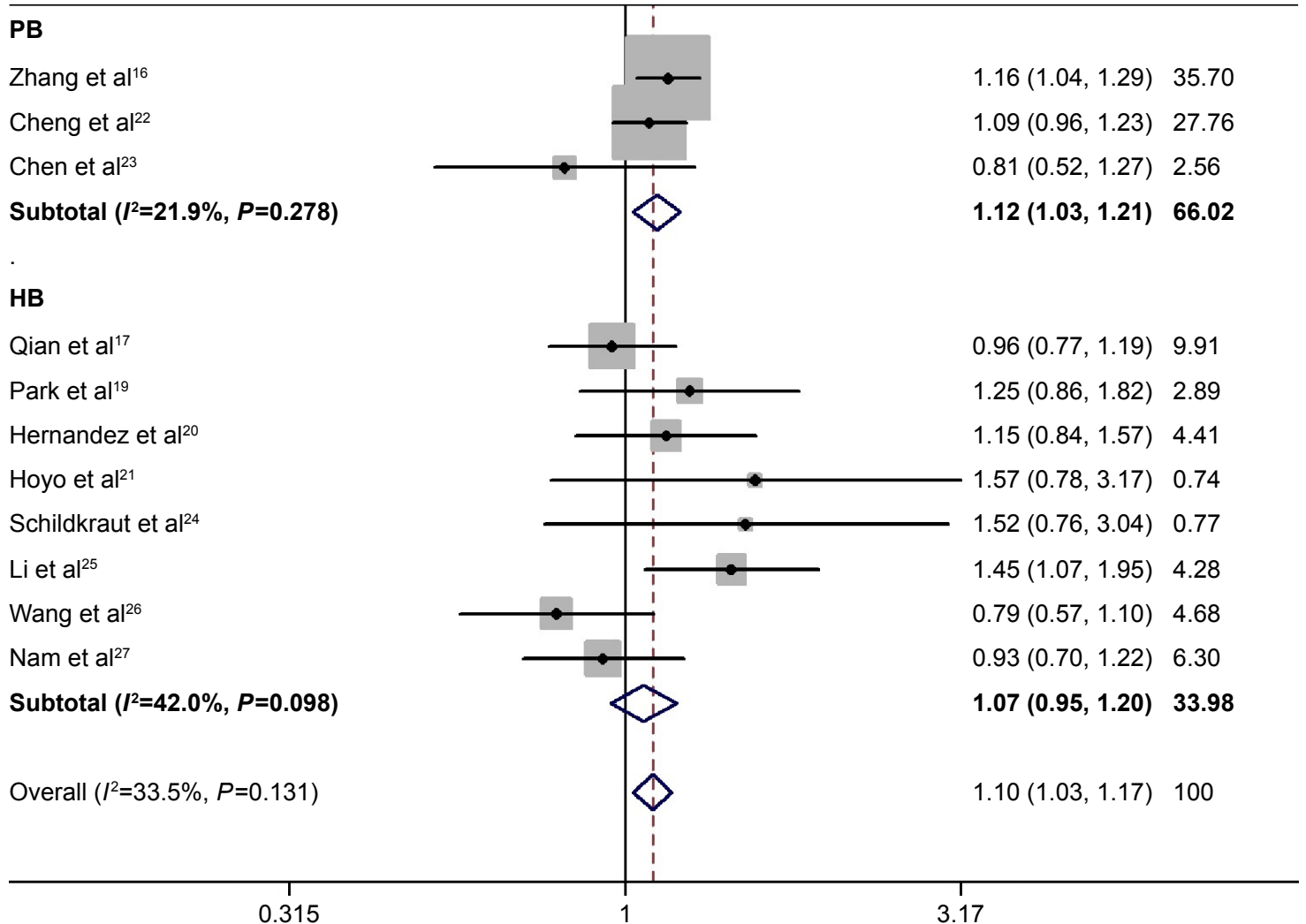

Figure 4 Forest plots of subgroup analysis of the association between IGFBP3 polymorphism and PCa susceptibility in the dominant model.

Notes: (A) Stratified by genotyping method; (B) stratified by source of controls.

Abbreviations: $\mathrm{Cl}$, confidence interval; HB, hospital-based controls; IGFBP3, insulin-like growth factor-binding protein-3; OR, odds ratio; PB, population-based controls; $\mathrm{PCa}$, prostate cancer; PCR-RLFP, polymerase chain reaction-restriction fragment length polymorphism.

determined in order to predict the occurrence, development, and clinical outcomes of $\mathrm{PCa} .{ }^{33}$ In addition, some studies suggested that PCa patients with the IGFBP $-202 \mathrm{~A} / \mathrm{C}$ variant allele had lower circulating IGFBP3 levels and an increased risk of prostate carcinogenesis, whereas other studies found that these polymorphisms might play a negative role against the increasing risk of PCa. This controversy could be caused by several factors, including the differences in study design, sample size, genotyping method, and statistical method. Therefore, this meta-analysis was performed to provide a
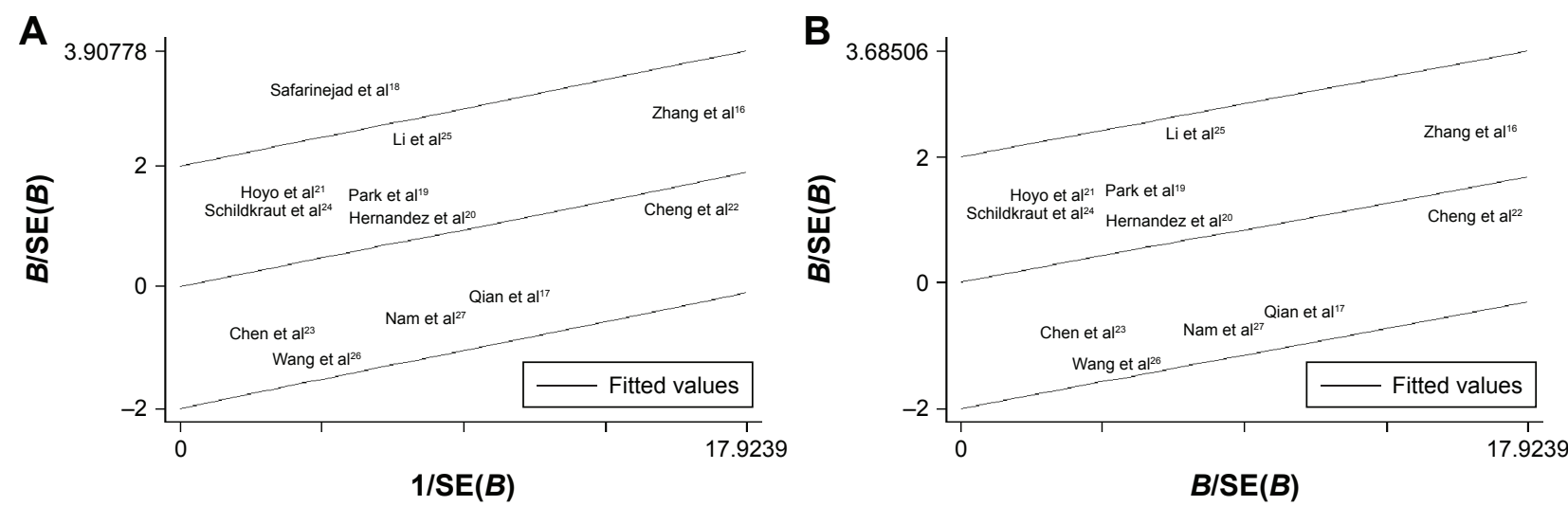

Figure 5 Galbraith plot of the association between IGFBP3 polymorphism and PCa susceptibility in the dominant model.

Notes: (A) Before removing a study by Safarinejad et al; ${ }^{18}$ (B) after the exclusion of the study.

Abbreviations: IGFBP3, insulin-like growth factor-binding protein-3; PCa, prostate cancer; SE, standard error. 

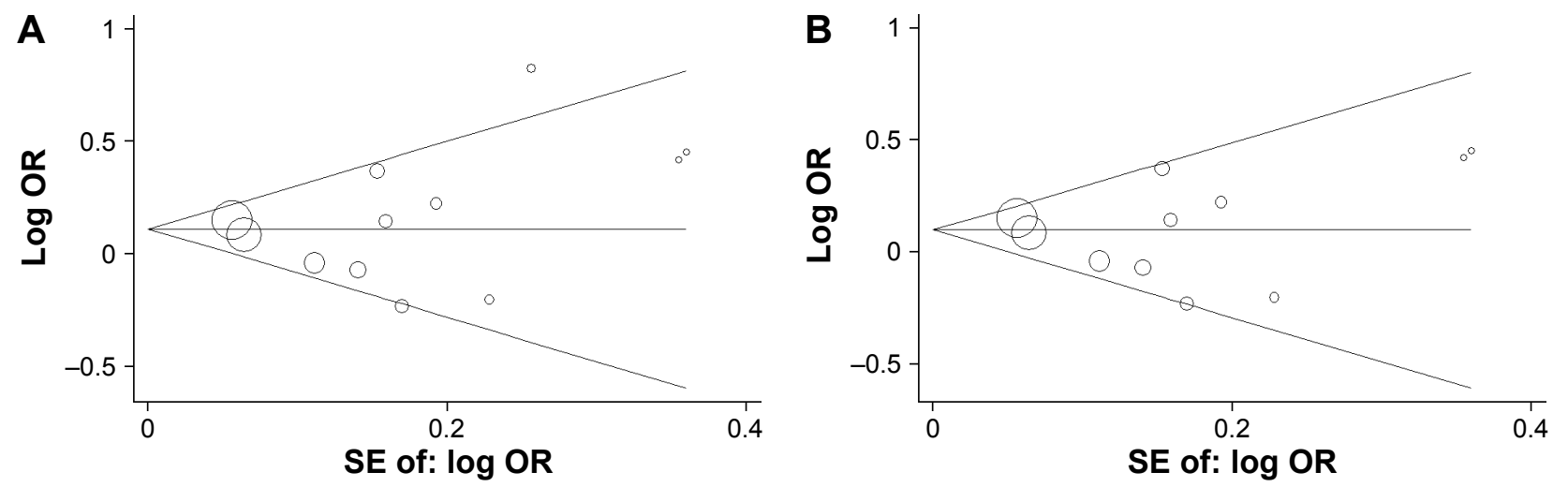

Figure 6 Begg's funnel plot of publication bias test.

Notes: (A) Before omitting a study of Safarinejad et al; ${ }^{18}$ (B) after the exclusion of the study.

Abbreviations: SE, standard error; OR, odds ratio.

more reliable conclusion about such associations between IGFBP3 polymorphisms and PCa risk.

Meta-analysis is a powerful tool that can provide superior results compared with a single study, especially in analyzing unexplained associations. ${ }^{34}$ As a result, it was found that there was a strong advantage to proving the association between rs 2854744 and PCa risk by using a meta-analysis. The present meta-analysis indicated that IGFBP3 gene polymorphism might influence PCa susceptibility.

In general, the previous case-control studies have described the associations between IGFBP3 -202 A/C polymorphism and $\mathrm{PCa}$ susceptibility. ${ }^{16-27}$ Nevertheless, the findings were still conflicting, likely because of the relatively small sample sizes of individual studies, the different sources of controls, the use of various genotyping methods, and the possible limited effect of the gene polymorphism on $\mathrm{PCa}$ susceptibility. All these factors contributed to the limited statistical power in the published studies. They suggested that significantly increased risk of $\mathrm{PCa}$ was associated with low circulating IGFBP3 levels in the hospital-based control group. ${ }^{35,36}$ Interestingly, in this meta-analysis, the outcomes were contrary. Therefore, a better method is required to analyze and understand the associations between IGFBP3 polymorphisms and the risk of $\mathrm{PCa}$. On the one hand, further stratified analyses were required in this meta-analysis. On the other hand, a meta-analysis was conducted to explain controversial conclusion, and this analysis provided the most comprehensive understanding of such associations to date.

After conducting the stratified analysis by the source of controls, the results showed that IGFBP $3-202 \mathrm{~A} / \mathrm{C}$ polymorphism was strongly associated with the risk of PCa only in the population-based control group. Moreover, the control groups included both healthy individuals and patients with diseases other than PCa. It was likely that different individuals in the control group might have different risks of developing PCa in subsequent years. This might affect the quality

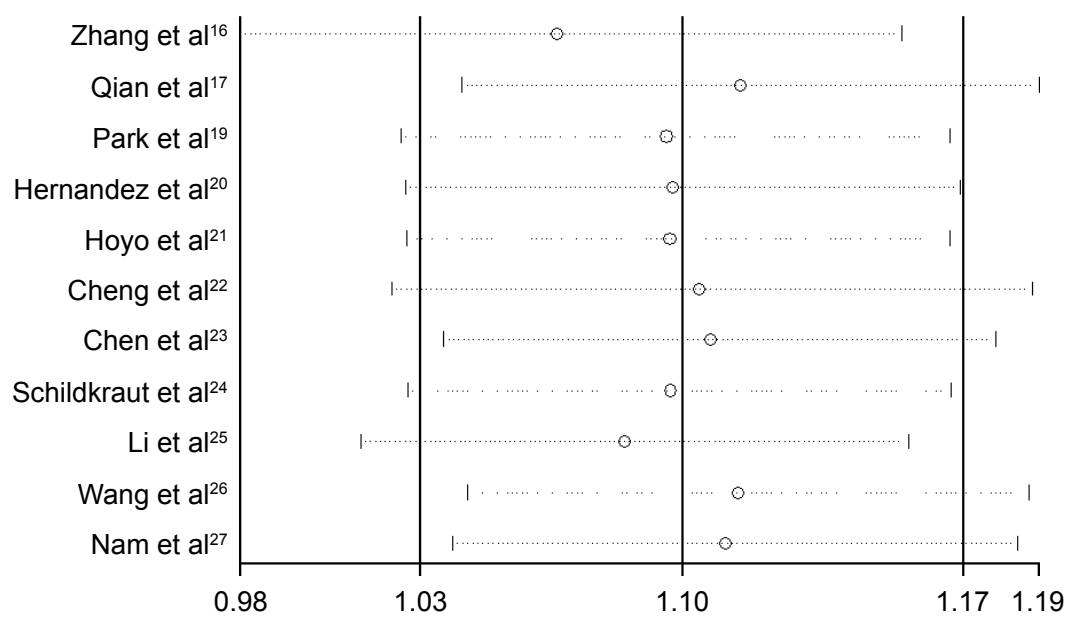

Figure 7 Sensitivity analysis under the dominant model. 
of the studies and make their results unreliable. Therefore, further research should analyze a population-based control group as far as possible in the future. In addition, unified enrollment criteria are required, and relevant studies with larger sample sizes should be selected.

In the subgroup analysis by genotyping method, a statistically significant increased risk of PCa was found in the Sequenom method group, but not in TaqMan or polymerase chain reaction-restriction fragment length polymorphism. Different genotyping methods have their own advantages, which might lead to different statistical results. In addition, the Sequenom method offers the advantage of discovering one site at a time, but it may lack the accuracy provided by TaqMan or polymerase chain reaction-restriction fragment length polymorphism. Therefore, only including studies conducted by using the same genotyping method would make the meta-analysis results more significant and reliable.

Although we had sufficient and robust statistical evidence in this analysis, including a large sample size that permitted weak associations to be estimated, some limitations of this analysis should be considered. First, the results were based on unadjusted estimates, but the effect of multiple confounders such as age, lifestyle, and environmental factors should be taken into consideration. Second, the majority of studies included were investigated in mixed populations, suggesting that the results of the analysis should be cautiously interpreted. Therefore, future research should pay attention to the influence of ethnicity factors. Furthermore, owing to the limited data for some genotypes, only the dominant model analysis could be used in all the included studies.

Thus, further studies providing comprehensive and detailed data for all the genotypes and models are required. Moreover, in this analysis, the controls were not uniformly defined, and they included both healthy individuals and patients with other diseases. Hence, it was found that nondifferential misclassification existed, because the control populations in these studies may have had different risks for developing PCa in the future. Furthermore, the number of studies in some subgroups was relatively small in the stratified analyses, resulting in insufficient statistical power to explore the potential association. Hence, the findings from this analysis need to be further confirmed with a sufficiently large number of participants in order to substantiate the previously reported associations in the existing, welldesigned studies.

\section{Conclusion}

This meta-analysis provided statistical evidence supporting the contention that the IGFBP3 -202 A/C gene polymorphism decreased PCa susceptibility, especially in studies with population-based controls and those used the Sequenom method. Therefore, screening for the IGFBP3 -202 A/C polymorphism might be a promising detection technology for assessing the risk of developing PCa.

\section{Disclosure}

The authors report no conflicts of interest in this work.

\section{References}

1. Siegel RL, Miller KD, Jemal A. Cancer statistics, 2016. CA Cancer J Clin. 2016;66(1):7-30.

2. Recine F, Sternberg CN. Hormonal therapy and chemotherapy in hormone-naive and castration resistant prostate cancer. Transl Androl Urol. 2015;4(3):355-364.

3. Schroder FH, Hugosson J, Roobol MJ, et al. Prostate-cancer mortality at 11 years of follow-up. $N$ Engl J Med. 2012;366(11):981-990.

4. Vijayvergia N, Denlinger CS. Lifestyle factors in cancer survivorship: where we are and where we are headed. J Pers Med. 2015;5(3):243-263.

5. Lin PH, Aronson W, Freedland SJ. Nutrition, dietary interventions and prostate cancer: the latest evidence. BMC Med. 2015;13:3.

6. Dotson SJ, Howard MD, Aung M, Keenan JA, Jolly PE. The epidemiology of prostate cancer in Western Jamaica: risk factors, knowledge, attitudes and practices. West Indian Med J. Epub ahead of print 2015 May 8.

7. Lai GY, Giovannucci EL, Pollak MN, et al. Association of C-peptide and leptin with prostate cancer incidence in the Health Professionals Follow-up Study. Cancer Causes Control. 2014;25(5):625-632.

8. Ross-Adams H, Lamb AD. The genetic classification of prostate cancer: what's on the horizon? Future Oncol. 2016;12(6):729-733.

9. Helfand BT, Catalona WJ. The epidemiology and clinical implications of genetic variation in prostate cancer. Urol Clin North Am. 2014;41(2): 277-297.

10. Liu B, Lee KW, Anzo M, et al. Insulin-like growth factor-binding protein-3 inhibition of prostate cancer growth involves suppression of angiogenesis. Oncogene. 2007;26(12):1811-1819.

11. Kaplan RC, Petersen AK, Chen MH, et al. A genome-wide association study identifies novel loci associated with circulating IGF-I and IGFBP-3. Hum Mol Genet. 2011;20(6):1241-1251.

12. Khandwala HM, McCutcheon IE, Flyvbjerg A, Friend KE. The effects of insulin-like growth factors on tumorigenesis and neoplastic growth. Endocr Rev. 2000;21(3):215-244.

13. Firth SM, Baxter RC. Cellular actions of the insulin-like growth factor binding proteins. Endocr Rev. 2002;23(6):824-854.

14. Baxter RC. Insulin-like growth factor (IGF)-binding proteins: interactions with IGFs and intrinsic bioactivities. Am J Physiol Endocrinol Metab. 2000;278(6):E967-E976.

15. Deal C, Ma J, Wilkin F, et al. Novel promoter polymorphism in insulin-like growth factor-binding protein-3: correlation with serum levels and interaction with known regulators. J Clin Endocrinol Metab. 2001;86(3):1274-1280.

16. Zhang G, Zhu Y, Liu F, Gu C, Chen H, Xu J, Ye D. Genetic variants in insulin-like growth factor binding protein-3 are associated with prostate cancer susceptibility in Eastern Chinese Han men. Onco Targets Ther. 2016;9:61-66.

17. Qian J, Zhou H, Chen J, et al. Genetic polymorphisms in IGF-I and IGFBP-3 are associated with prostate cancer in the Chinese population. PLoS One. 2014;9(2):e85609.

18. Safarinejad MR, Shafiei N, Safarinejad S. Relationship of insulin-like growth factor (IGF) binding protein-3 (IGFBP-3) gene polymorphism with the susceptibility to development of prostate cancer and influence on serum levels of IGF-I, and IGFBP-3. Growth Horm IGF Res. 2011; 21(3):146-154.

19. Park K, Kim JH, Jeon HG, Byun SS, Lee E. Influence of IGFBP3 gene polymorphisms on IGFBP3 serum levels and the risk of prostate cancer in low-risk Korean men. Urology. 2010;75(6):1511-1516. 
20. Hernandez W, Grenade C, Santos ER, Bonilla C, Ahaghotu C, Kittles RA. IGF-1 and IGFBP-3 gene variants influence on serum levels and prostate cancer risk in African-Americans. Carcinogenesis. 2007;28(10): 2154-2159.

21. Hoyo C, Grubber J, Demark-Wahnefried W, et al. Grade-specific prostate cancer associations of IGF1 (CA)19 repeats and IGFBP3-202A/C in blacks and whites. $J$ Natl Med Assoc. 2007;99(7):718-722.

22. Cheng I, Penney KL, Stram DO, et al. Haplotype-based association studies of IGFBP1 and IGFBP3 with prostate and breast cancer risk: the multiethnic cohort. Cancer Epidemiol Biomarkers Prev. 2006; 15(10):1993-1997.

23. Chen C, Freeman R, Voigt LF, Fitzpatrick A, Plymate SR, Weiss NS. Prostate cancer risk in relation to selected genetic polymorphisms in insulin-like growth factor-I, insulin-like growth factor binding protein-3, and insulin-like growth factor-I receptor. Cancer Epidemiol Biomarkers Prev. 2006;15(12):2461-2466.

24. Schildkraut JM, Demark-Wahnefried W, Wenham RM, et al. IGF1 (CA) 19 repeat and IGFBP3 -202 A/C genotypes and the risk of prostate cancer in Black and White men. Cancer Epidemiol Biomarkers Prev. 2005;14(2):403-408.

25. Li L, Cicek MS, Casey G, Witte JS. No association between genetic polymorphisms in IGF-I and IGFBP-3 and prostate cancer. Cancer Epidemiol Biomarkers Prev. 2004;13(3):497-498.

26. Wang L, Habuchi T, Tsuchiya N, et al. Insulin-like growth factor-binding protein-3 gene -202 A/C polymorphism is correlated with advanced disease status in prostate cancer. Cancer Res. 2003;63(15):4407-4411.

27. Nam RK, Zhang WW, Trachtenberg J, et al. Comprehensive assessment of candidate genes and serological markers for the detection of prostate cancer. Cancer Epidemiol Biomarkers Prev. 2003;12(12): 1429-1437.
28. Guo SW, Thompson EA. Performing the exact test of Hardy-Weinberg proportion for multiple alleles. Biometrics. 1992;48(2):361-372.

29. Hayashino Y, Noguchi Y, Fukui T. Systematic evaluation and comparison of statistical tests for publication bias. J Epidemiol. 2005;15(6): 235-243.

30. Giovannucci E. Insulin, insulin-like growth factors and colon cancer: a review of the evidence. J Nutr. 2001;131(11 Suppl):3109S-3120S.

31. Baxter RC. Signalling pathways involved in antiproliferative effects of IGFBP-3: a review. Mol Pathol. 2001;54(3):145-148.

32. Ferry RJ, Katz LE, Grimberg A, Cohen P, Weinzimer SA. Cellular actions of insulin-like growth factor binding proteins. Horm Metab Res. 1999;31(2-3):192-202.

33. Poole EM, Tworoger SS, Hankinson SE, Baer HJ. Genetic variability in IGF-1 and IGFBP-3 and body size in early life. BMC Public Health. 2012;12:659.

34. Munafo MR, Clark TG, Flint J. Assessing publication bias in genetic association studies: evidence from a recent meta-analysis. Psychiatry Res. 2004;129(1):39-44.

35. Ding Q, Shi Y, Fan B, Fan Z, Wang J. IGFBP-3 promoter polymorphism -202A $>$ C (rs2854774) contributes to prostate cancer risk: evidence based on 9,482 subjects. Urol Int. 2014;93(1):100-107.

36. Mao YQ, Xu X, Lin YW, et al. Prostate cancer risk in relation to a single nucleotide polymorphism in the insulin-like growth factor-binding protein-3 (IGFBP3) gene: a meta-analysis. Asian Pac J Cancer Prev. 2012;13(12):6299-6303.
OncoTargets and Therapy

\section{Publish your work in this journal}

OncoTargets and Therapy is an international, peer-reviewed, open access journal focusing on the pathological basis of all cancers, potential targets for therapy and treatment protocols employed to improve the management of cancer patients. The journal also focuses on the impact of management programs and new therapeutic agents and protocols on

\section{Dovepress}

patient perspectives such as quality of life, adherence and satisfaction. The manuscript management system is completely online and includes a very quick and fair peer-review system, which is all easy to use. Visit http://www.dovepress.com/testimonials.php to read real quotes from published authors. 